\title{
Calculation Model and Influencing Factors of Surrounding Rock Loosening Pressure for Tunnel in Fold Zone
}

\author{
Jianhao Liu, Caijin Xie $\mathbb{D}^{\mathrm{D}}$, and Junying Rao \\ School of Civil Engineering, Guizhou University, Guiyang, Guizhou Province 550025, China \\ Correspondence should be addressed to Caijin Xie; jyrao@gzu.edu.cn
}

Received 25 November 2020; Revised 7 December 2020; Accepted 21 January 2021; Published 8 February 2021

Academic Editor: Ma Jianjun

Copyright (C) 2021 Jianhao Liu et al. This is an open access article distributed under the Creative Commons Attribution License, which permits unrestricted use, distribution, and reproduction in any medium, provided the original work is properly cited.

\begin{abstract}
This research aims to study the surrounding rock loosening pressure variation law of tunnel in the fold area. Based on the calculation method of surrounding rock loosening pressure for shallow tunnel, a new calculation model of the surrounding rock pressure was proposed for tunnel in the fold area; through this calculation model, the effects of tectonic stress $(F)$, the angle $\left(\varphi_{1}\right)$ between tectonic stress and horizontal plane, tunnel buried depth $(h)$, friction angle $(\theta)$, the multiple $(k)$ between tectonic stress and rock mass gravity in the upper part of the tunnel, lateral pressure coefficient $(\lambda)$, and tunnel midline offset $(t)$ on tunnel surrounding rock loosening pressure in fold area are studied, respectively. Results show that in the anticline area, when $\varphi_{1}$ increases, the vertical loosening pressure $(q)$ decreases; when $q>0$, the surrounding rock is in the elastic deformation stage, and $q$ decreases monotonously as $F$ increases; when $q<0$, the rock mass is in the initial stage of failure, and as $F$ continues to increase, the number of internal cracks increases, the rock mass reaches its ultimate bearing capacity and then fails completely, and $q$ increases linearly in this process; $q$ decreases with the increase of $\theta$ and $k$; the greater $k$ is, the easier it is to reach its bearing limit; the horizontal loosening pressure $(e)$ increased monotonously with the increase of $h$ and $\lambda$. The research process of surrounding rock loosening pressure of tunnel in the syncline area is similar to that of tunnel in the anticline area; $q$ decreases with the increase of $\theta$ and $\lambda ; q$ monotonically increases with $F$ increasing.
\end{abstract}

\section{Introduction}

For basic transportation construction in complex topography and geomorphic areas, tunnels have become an important part of basic transportation due to their unique advantages. Over the years, as the mileage of the tunnel is getting longer and longer, the geological conditions encountered become more and more complex. If the stress conditions of the surrounding rock of the tunnel are not found out, it will be very dangerous to the reckless construction of the tunnel. However, the surrounding rock loosening pressure is the pressure directly acting on the supporting structure by the gravity of loosened or collapsed rock mass. The quantity, property, and distribution law of surrounding rock loosening pressure play an important role in the design, construction, and operation of the supporting system [1-7]. If tunnel is not supported timely after excavation, there will be a transfixion sliding surface in surrounding rock. The rock mass will gradually collapse and move and then develop into a subsidence area eventually (as shown in Figure 1). Scholars have done a lot of work on the research on the loosening pressure of tunnel surrounding rock, such as, the upper bound theorem was one of the theories to analyze the surrounding rock pressure of tunnel [8], but its calculation principle and process were complicated, which was unfavorable to engineering application; the numerical method and empirical method were the common methods to analyze the surrounding rock pressure of shallow tunnel under unsymmetrical pressure [9]; the surrounding rock deformation curve and support characteristic curve could also be used to evaluate the stability of tunnel surrounding rock [10]. Sugimoto et al. considered the soil pressure caused by the active lateral displacement of the surface after tunnel excavation and the displacement caused by the 




(a)

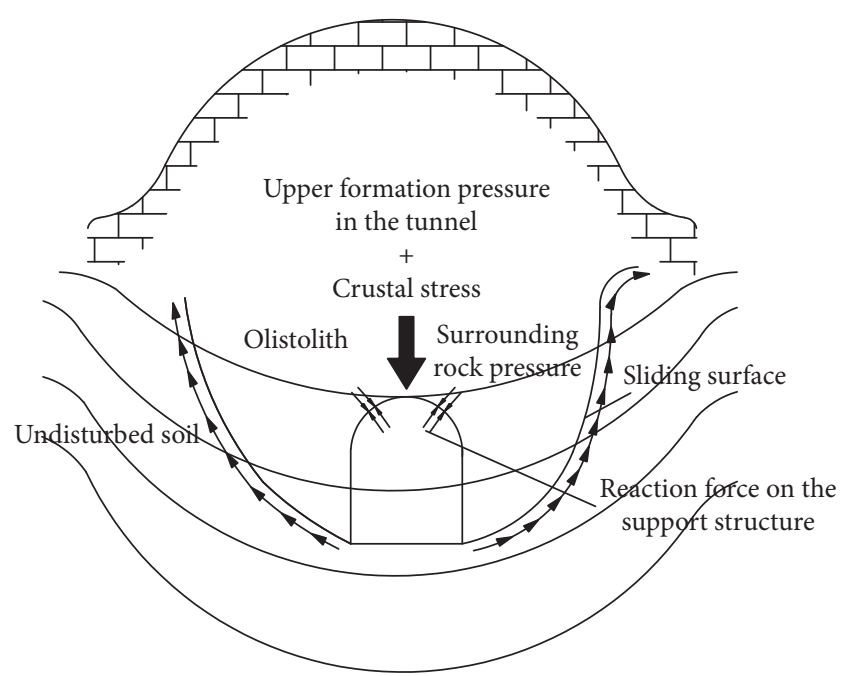

(b)

Figure 1: Surrounding rock loosening pressure of tunnel in the fold zone. (a) Anticline area. (b) Oblique area.

deformation before the stability of the surrounding rock; they studied the soil pressure, displacement, and section force of the lining by changing the reaction coefficient of the roadbed and the grouting rate [11]. According to the calculation theory of surrounding rock pressure of shallow tunnel, linear failure criterion and nonlinear failure criterion were commonly used [12]. Based on the structural stress of shallow unsymmetrical loading tunnel with variable slope surface, Liu and Fang derived the calculation formula of the loosening surrounding rock pressure in the shallow bilateral bias tunnel [13]. Li et al. put forward the loose pressure calculation theory of deep buried double holes by modifying Protodyakonov equilibrium arch theory and studied the effects of clear distance of double holes, reinforcement coefficient, excavation span, and excavation height on surrounding rock stress [14]. Sugimoto et al. proposed an analysis model of tunnel lining frame structure based on nonlinear ground response curve. Considering passive earth pressure and active earth pressure, the model could better reflect the influence of different surrounding rock on lining earth pressure, lining displacement, and lining section force [15]. Based on two-linear-spring design, Shakeri et al. simulated the imperfect boundary conditions between surrounding rock and tunnel. The dynamic circumferential stress and solid displacement of tunnel surrounding rock were studied by using infinite Bessel series, Hankel series, Laplace transform, and the associated Durbin algorithm [16].

It is found that although there are abundant achievements on the surrounding rock loosening pressure of the tunnel, these results do not involve tunnel in fold area. However, tunnels are often built in the fold zone [17-20]. It is necessary and significant to study the surrounding rock pressure in the fold zone. Therefore, this paper analyzes the calculation model and influencing factors of the loose pressure of the surrounding rock of the tunnel in the fold zone, providing a basis for the design and construction of tunnels with folds.

\section{Assumptions}

According to the movement trend and stress characteristics of surrounding rock after the tunnel excavation in the fold zone, a simplified calculation model is established as shown in Figure 2. The calculated model takes the longitudinal length of the tunnel as $1 \mathrm{~m}$ as research object, which can transform the three-dimensional model into a two-dimensional plane model $[21,22]$.

There are two cases of the stability analysis of tunnel according to the relation between buried depth $(h)$ and equivalent load height $\left(h_{q}\right)$. When $h>h_{q}$, the friction resistance of the sliding surface increases with the thickness of upper rock mass increasing. The influence of sliding surface resistance should be considered when analyzing the surrounding rock loosening pressure. If $h \leq h_{q}$, it can be ignored.

\section{Simplified Calculation Model}

The calculation models of tunnel in the fold zone are simplified as follows:

(1) Based on the geological tectonics, the surface material above the anticline tunnel is loose and eroded to form a valley, so it is simplified as " $V$ " shape (Figure 2(a)). The surface material right above the oblique zone tunnel is tight and does not easily erode. On the contrary, the surface material on both sides erodes more easily. The shape of mountain is simplified as " $\wedge$ " (Figure 2(b)).

(2) The fracture surface formed in the rock mass is simplified into the oblique faces of $\mathrm{AC}$ and $\mathrm{BD}$. The angle between $\mathrm{AC}$ (or $\mathrm{BD}$ ) and $x$ axis is $\beta$.

(3) When the roof rock (EFGH) sinks, as it is blocked by both sides of the three-ridge rock body (AEC and $\mathrm{BDF}$ ), it will drive the three-ridge rock down together, and when the whole rock declines, it will be 




(a)



(b)

FiguRE 2: Simplified calculation models of surrounding rock loosening pressure for tunnel in the fold zone. (a) Anticline zone tunnel. (b) Oblique zone tunnel.

hindered by the undisturbed rock. Similar to the force, the gravity of the roof rock is $W_{1}$, the gravity of the three-ridge rock masses on both sides is $W_{2}$, and the resistance of the sinking rock (EFGH) given by the three-ridge rock is $T(T=T 1+\mathrm{t} 2)$. When the rock (EFGH) is sinking, the resistance given by undisturbed rock masses on both sides is $N$. The rock mass in the anticline zone is subjected to the tectonic stress $(F)$ and $F$ is at an angle $\left(\varphi_{1}\right)$ to the horizontal. The rock in the oblique zone is subjected to a vertical downward tectonic stress $(F)$.

(4) The shear strength of $\mathrm{AC}$ and $\mathrm{BD}$ at the oblique plane depends on the inner friction angle $(\varphi)$ and the cohesion force $(c)$ of the sliding surface. In order to simplify the calculation, the equivalent inner friction angle $\varphi_{0}$ is introduced. The friction angle between the roof rock and the three-ridge rock is $\theta$. The relation between $\theta$ and $\varphi_{0}$ is shown in Table 1 . The values of specific frictional angle $\theta$ of various types of surrounding rocks and equivalent inner friction angle $\varphi_{0}$ are shown in Table $2[23,24]$.

\section{Loosening Rock Pressure Model of Tunnel in the Anticline Zone}

The loosening rock pressure model of tunnel in the anticline zone can be divided into two situations: (1) the anticlinal axis parallel to tunnel centerline, as shown in Figure 2(a); (2) the anticlinal axis intersecting tunnel centerline, as shown in Figure 3.

4.1. Anticlinal Axis Parallel to Tunnel Centerline. Based on the above assumptions, it can be seem from the corresponding mechanical principle that the total vertical pressure acting on the support structure is

$$
P=W_{1}-2 T_{1} \sin \theta-2 F \sin \phi_{1},
$$

where $W_{1}$ is the gravity of the roof covering rock mass (EFHG), $W_{1}=1 / 2 \gamma\left(h_{1}+h_{0}\right) B, B$ is the tunnel width, $T 1$ is the entrainment force of two-sided three-ridge rock against the rock EFHG, and $F$ is the crustal stress in the fold zone.

Because $T 1$ is unknown, we take the three-ridge rock $\mathrm{BDF}$ as a study object. Its force analysis is shown in Figure 4.

The gravity of three-ridge rock BDF is $W_{2}$ :

$$
W_{2}=\frac{1}{2} \gamma h^{2} \frac{1}{\tan \alpha-\tan \beta}
$$

where $\gamma$ is the density of rock, $h$ is the buried depth of tunnel, and $\beta$ and $\alpha$ are shown in Figure 2(a).

From the trigonometric function theorem, we obtain

$$
\frac{T}{\sin \left[90^{\circ}+\left(\varphi_{0}-\varphi_{1}-\beta\right)\right]}=\frac{W_{2}}{\sin \left(\varphi_{1}+\beta-\varphi_{0}-\theta\right)} .
$$

Equation (3) can be simplified as

$$
T=\frac{W_{2} \sin \left[90^{\circ}+\left(\varphi_{0}-\varphi_{1}-\beta\right)\right]}{\sin \left(\varphi_{1}+\beta-\varphi_{0}-\theta\right)}=W_{2}\left[\frac{1}{\tan \left(\varphi_{1}+\beta-\varphi_{0}-\theta\right)}-\tan \theta\right] \cos \theta
$$


TABLE 1: Relationship between $\theta$ and $\varphi_{0}$ values.

\begin{tabular}{lccc}
\hline Equivalent inner friction angle $\varphi_{0}\left(^{\circ}\right)$ & $\theta$ & Equivalent inner friction angle $\varphi_{0}\left(^{\circ}\right)$ & $\theta$ \\
\hline$<20$ & $(0 \sim 0.1) \varphi_{0}$ & $45 \sim 50$ & $(0.5 \sim 0.6) \varphi_{0}$ \\
$20 \sim 30$ & $(0.1 \sim 0.2) \varphi_{0}$ & $50 \sim 55$ & $(0.6 \sim 0.7) \varphi_{0}$ \\
$30 \sim 35$ & $(0.2 \sim 0.3) \varphi_{0}$ & $55 \sim 60$ & $(0.7 \sim 0.8) \varphi_{0}$ \\
$35 \sim 40$ & $(0.3 \sim 0.4) \varphi_{0}$ & $60 \sim 65$ & $(0.8 \sim 0.9) \varphi_{0}$ \\
$40 \sim 45$ & $(0.4 \sim 0.5) \varphi_{0}$ & $>65$ & $0.9 \varphi_{0}$ \\
\hline
\end{tabular}

TABLE 2: $\theta$ and $\varphi_{0}$ calculated values.

\begin{tabular}{lcccccc}
\hline Surrounding rock level & I & II & III & IV & V & VI \\
\hline$\theta\left({ }^{\circ}\right)$ & 73 & 60 & 43 & 23 & 7.5 \\
$\varphi_{0}\left({ }^{\circ}\right)$ & $>78$ & $67 \sim 78$ & $55 \sim 66$ & $43 \sim 54$ & $31 \sim 42$ & $<30$ \\
\hline
\end{tabular}

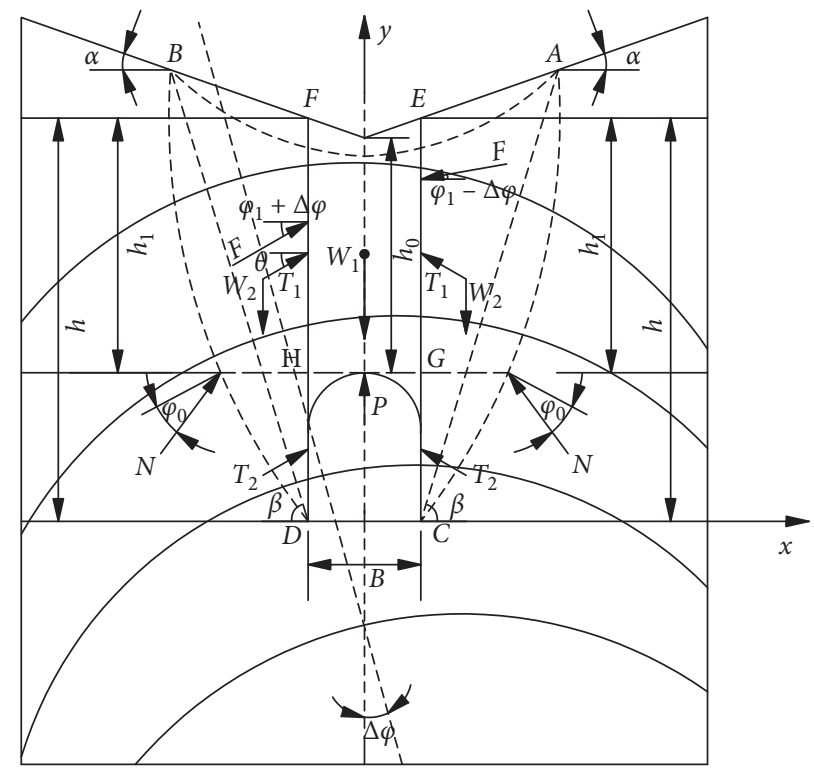

FIGURE 3: Loosening rock pressure model when the anticlinal axis has an intersection with tunnel centerline.

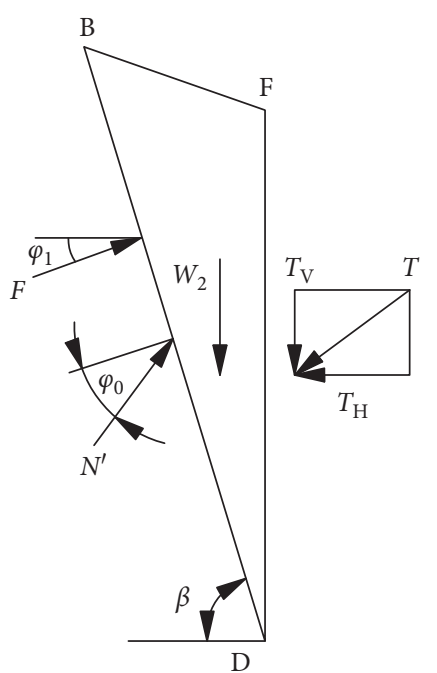

(a)

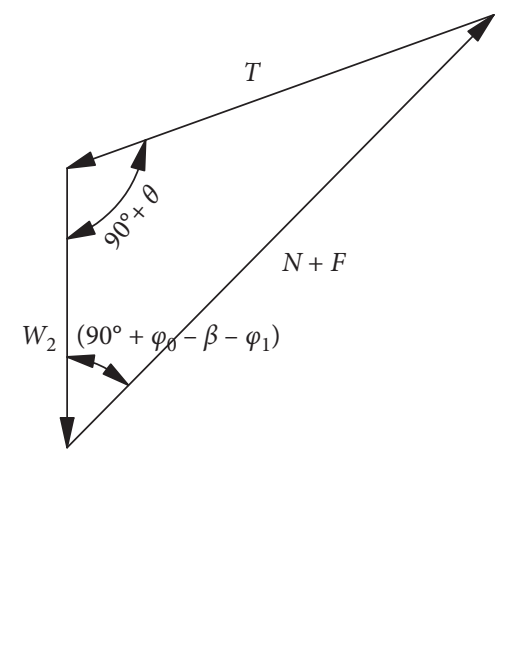

(b)



(c)

FIGURE 4: Stress analysis of the triangular rock BDF and the apex rock EFHG. 
By substituting equation (2) into equation (4), we obtain $T=\frac{1}{2} \gamma h^{2} \frac{1}{\tan \alpha-\tan \beta}\left[\frac{1}{\tan \left(\varphi_{1}+\beta-\varphi_{0}-\theta\right)}-\tan \theta\right] \cos \theta$.

Make

$$
\lambda=\frac{1}{\tan \alpha-\tan \beta}\left[\frac{1}{\tan \left(\varphi_{1}+\beta-\varphi_{0}-\theta\right)}-\tan \theta\right] \cos \theta .
$$

Thus,

$$
T=\frac{1}{2} \gamma h^{2} \lambda
$$

In equation (5) to equation (7), $\lambda$ is coefficient of lateral pressure.

The entrainment force of two-sided three-ridge rock against the rock EFHG is T1, which can be shown as follows:

$$
T_{1}=\frac{1}{2} \gamma h_{1}^{2} \lambda
$$

where $\lambda$ is a function of $\varphi_{0}, \theta$, and $\beta$, as shown in equation (6). $\varphi_{0}$ and $\theta$ are known quantities, and $\beta$ is an unknown quantity. According to the calculation model in Figure 2(a), when the rock EFGH begins to slide, the position of the sliding surface is most likely at the maximum sliding force $T$; at the same time, it is at the sliding surface of two-sided three-ridge rock. Therefore, we need to use the concept of extreme value to solve this problem.

By letting $\mathrm{d} \lambda / \mathrm{d} \beta=0$, we can obtain

$$
\frac{d\left\{1 / \tan \alpha-\tan \beta\left[1 / \tan \left(\phi_{1}+\beta-\phi_{0}-\theta\right)-\tan \theta\right] \cos \theta\right\}}{d \beta}=0 \text {. }
$$

Equation (9) can be simplified as

$$
\begin{aligned}
& \tan ^{2} \beta\left\{\frac{1}{2} \sin \left[2\left(\varphi_{1}-\varphi_{0}-\theta\right)\right]+\tan \theta \cos \left(\varphi_{1}-\varphi_{0}-\theta\right)\right\}+\tan \beta\left\{2 \sin ^{2}\left(\varphi_{1}-\varphi_{0}-\theta\right)+\tan \theta \sin \left[2\left(\varphi_{1}-\varphi_{0}-\theta\right)\right]\right\} \\
& \quad+\left\{\tan \alpha-\frac{1}{2} \sin \left[2\left(\varphi_{1}-\varphi_{0}-\theta\right)\right]-\tan \theta \sin ^{2}\left(\varphi_{1}-\varphi_{0}-\theta\right)\right\}=0
\end{aligned}
$$

We obtain

$$
\tan \beta=-\left(2 \sin ^{2} D+\tan \theta \sin 2 D\right)+\sqrt{\frac{\left(2 \sin ^{2} D+\tan \theta \sin 2 D\right)^{2}-4(1 / 2 \sin 2 D+\tan \theta \cos D)}{\sin 2 D+2 \tan \theta \cos D}},
$$

where $D=\left(\varphi_{1}-\varphi_{0}-\theta\right)^{\circ}$

Then, the total surrounding rock pressure $(P)$ is

$$
P=W_{1}-\gamma h_{1}^{2} \lambda \sin \theta-2 F \sin \varphi_{1} .
$$

Finally, we can obtain the surrounding rock pressure $(P)$ as

$$
P=\frac{1}{2} \gamma\left(h_{1}+h_{0}\right) B-\gamma h_{1}^{2} \lambda \sin \theta-2 F \sin \phi_{1} .
$$

The vertical surrounding rock loosening pressure is $q$, which can be shown as follows:

$$
q=\frac{P}{B}=\frac{1 / 2 \gamma\left(h_{1}+h_{0}\right) B-\gamma h_{1}^{2} \lambda \sin \theta-2 F \sin \varphi_{1}}{B} .
$$

The horizontal pressure at the top and bottom of the tunnel is

$$
\left\{\begin{array}{l}
e_{1}=\gamma h_{1} \lambda \\
e_{2}=\gamma h \lambda
\end{array}\right.
$$

4.1.1. The Influence of $\varphi_{1}$ on $q$ under the Condition of Different Surrounding Rock Grades When $\lambda$ Is Different. Take the section of a single line tunnel as an example; the soil bulk density $(\gamma)$ is $19 \mathrm{kN} / \mathrm{m}^{3}$, and the demarcation depth of tunnel depth $h_{p}=20.6 \mathrm{~m}$. So, take $h 1=14 \mathrm{~m}, h 0=12 \mathrm{~m}$, the tunnel net width $B=5 \mathrm{~m}$, lateral pressure coefficient $\lambda=(0 \sim 1.0)$, and crustal stress $F=1000 \mathrm{kN}$. The curves of the formation compression stress in the anticline zone with the angle $\varphi_{1}$ of horizontal plane and the vertical loosening pressure $(q)$ of surrounding rock (the curve of $\varphi_{1} \sim \mathrm{q}$ ) are shown in Figures 5(a)-5(f). By analyzing the curve of $\varphi_{1} \sim \mathrm{q}$, we can know that when $\varphi_{1}$ is increasing, the vertical loosening pressure of surrounding rock is in decline in different lateral pressure coefficients. When frictional angle $\theta=7.5^{\circ}$, tunnel VI level of surrounding rock is in the surrounding rock loosening vertical pressure value maximum. When frictional angle $\theta=73^{\circ}$, tunnel I level of surrounding rock is in the surrounding rock loosening vertical pressure value minimum.

4.1.2. The Influence of F on $q$ under the Condition of Different $\lambda$ When Surrounding Rock Grades Are Different. In order to study the influence of tectonic stress $(F)$ on surrounding rock loosening pressure $(q)$, now take $\varphi_{1}=30^{\circ}$. The relationship of $\mathrm{F}$ in the anticline zone and surrounding rock 


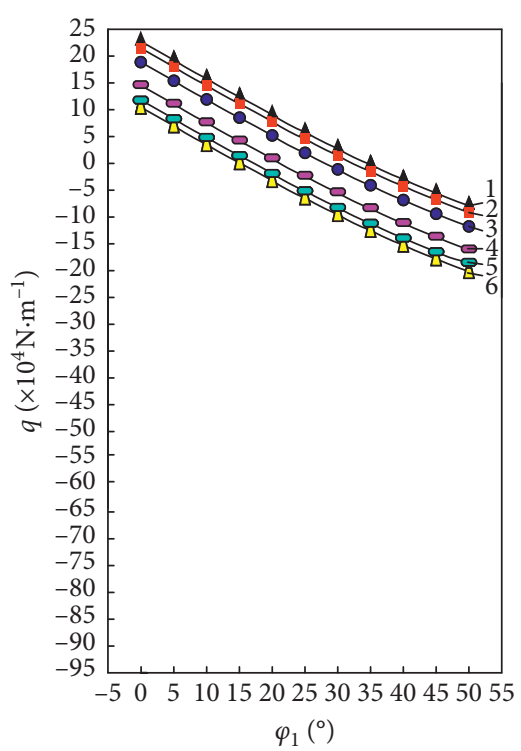

(a)

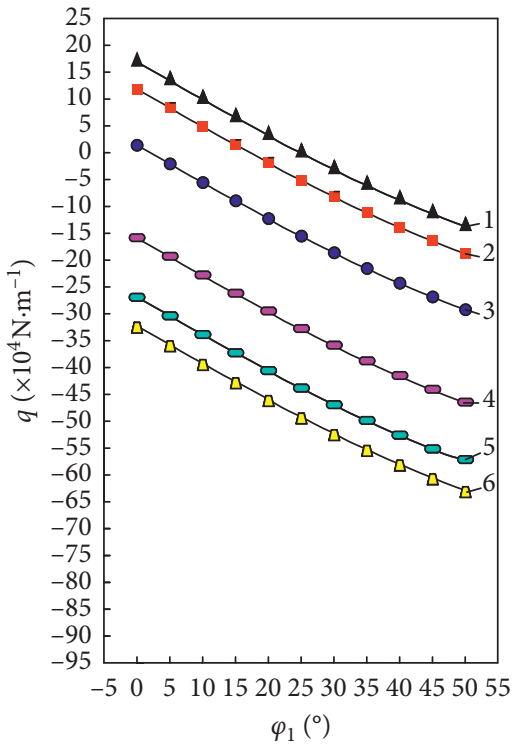

(d)



(b)

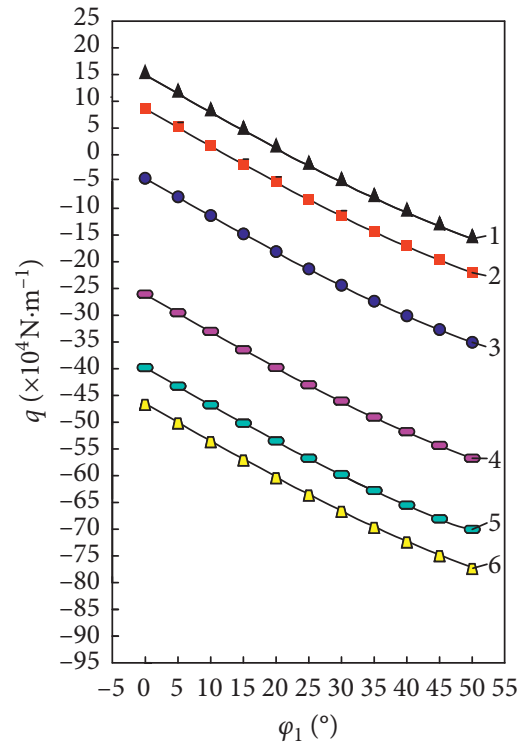

(e)



(c)

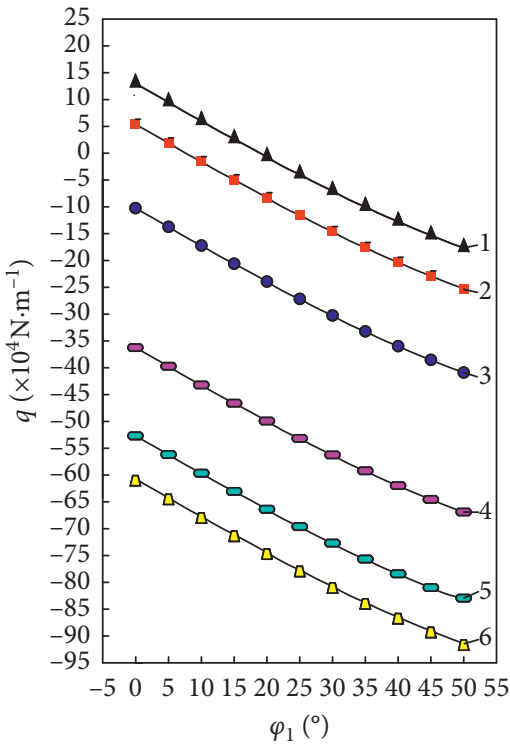

(f)

FIgURE 5: Relationship between $\varphi_{1}$ and vertical looseness pressure q of surrounding rock. (a) Side pressure coefficient $\lambda=0.2$. (b) Side pressure coefficient $\lambda=0.4$. (c) Side pressure coefficient $\lambda=0.6$. (d) Side pressure coefficient $\lambda=0.8$. (e) Side pressure coefficient $\lambda=1.0$. (f) Side pressure coefficient $\lambda=1.2 .1-\theta=7.5^{\circ} ; 2-\theta=12.5^{\circ} ; 3-\theta=23^{\circ} ; 4-\theta=43^{\circ} ; 5-\theta=60^{\circ} ; 6-\theta=73^{\circ}$.

loosening pressure $(q)$ is shown in Figures 6(a)-6(f), in different surrounding rock levels. When $q>0$, the surrounding rock is in elastic deformation stage. As the crustal stress increase, the surrounding rock loosening pressure decreases gradually. When $q<0$, the surrounding rock has been damaged. As the crustal stress increases, $q$ increases inversely. The function curves show that the tunnel is in I, II, and III surrounding rock levels, and the loosening pressure is less; when the tunnel is in IV, V, and VI surrounding rock levels, the loosening pressure is greater. Therefore, it is necessary to strengthen the supporting structure when building a tunnel in IV, V, and VI surrounding rock levels with the influence of tectonic stress.
Figure 7 shows the F-q curve. When $q$ decreases gradually, the first stage is the compaction stage of the rock mass; as the ground stress increases, the pores and fissures in the rock mass are gradually compacted, and the loose pressure appears "upward convex" at this time. The second stage is the stage of elastic deformation of rock mass, when the relationship between ground stress and loosening pressure is nearly linear. As the ground stress continues to increase, it is about to enter the third stage; cracks in the rock mass begin to form and gradually expand. However, when $q$ decreases to 0 , the failure of rock mass begins, and the number of cracks in the rock mass continues to increase and run through. With the continuous increase of $F$, when the rock mass 




(a)

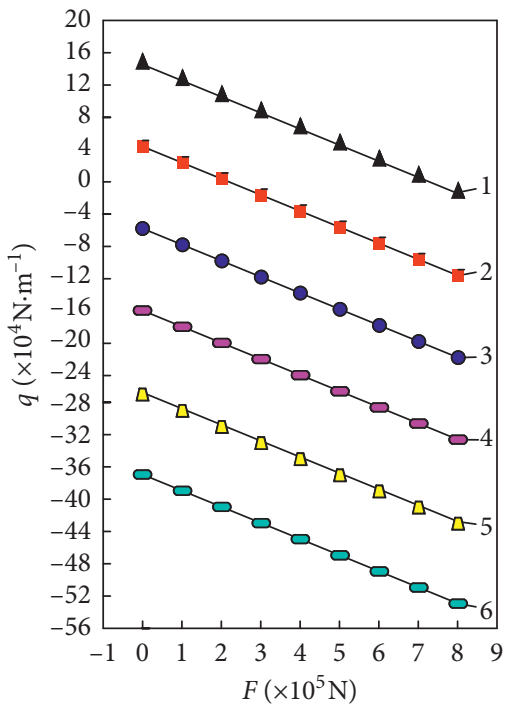

(d)

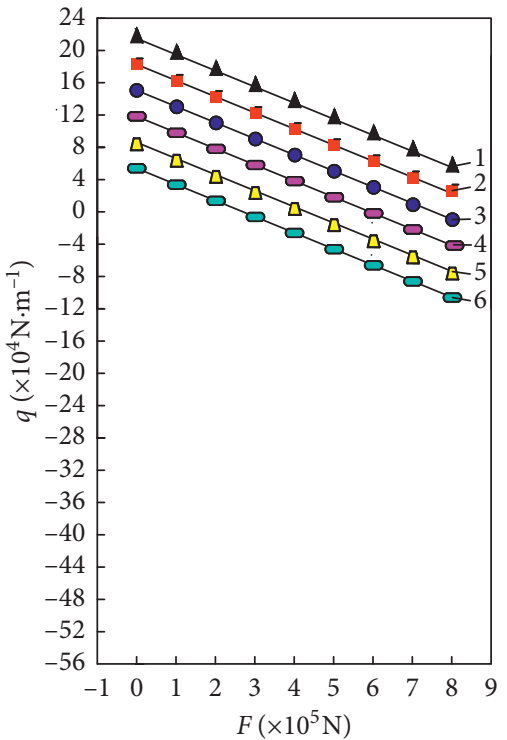

(b)



(e)

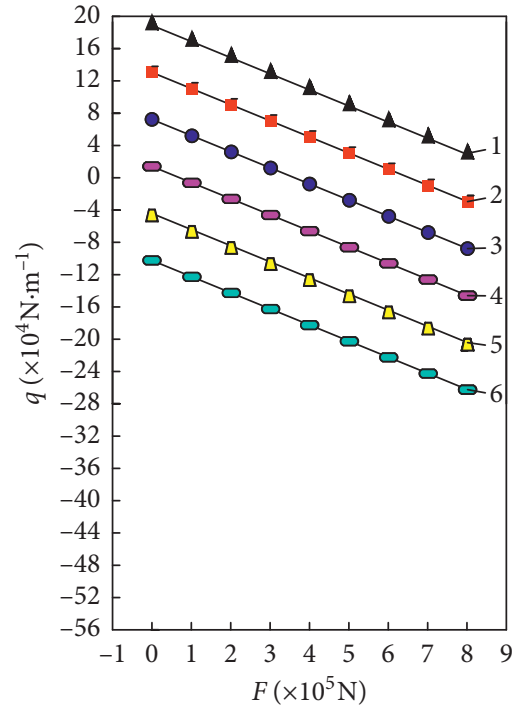

(c)

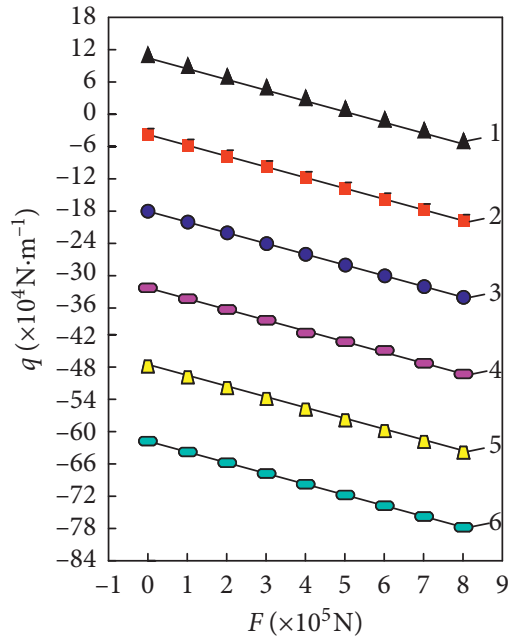

(f)

Figure 6: Relationship between geological tectonic stress $\mathrm{F}$ and surrounding rock loosening pressure (q). (a) Class VI surrounding rock zone, $\theta=7.5^{\circ}$. (b) Class V surrounding rock zone, $\theta=12.5^{\circ}$. (c) Class IV surrounding rock zone, $\theta=23^{\circ}$. (d) Class III surrounding rock zone, $\theta=43^{\circ}$. (e) Class II surrounding rock zone, $\theta=60^{\circ}$. (f) Class I surrounding rock zone, $\theta=73^{\circ}$. $1-\lambda=0.2 ; 2-\lambda=0.4 ; 3-\lambda=0.6 ; 4-\lambda=0.8$; $5-\lambda=1.0 ; 6-\lambda=1.2$.

reaches the bearing limit, the rock mass is completely destroyed and $q$ increases linearly in the opposite direction.

\subsubsection{The Influence of $\theta$ on $q$ under Different $k$ Conditions.} In actual project, the surrounding rock level changes frequently and the vertical surrounding rock loose pressure is analyzed in response to the continuous change of the surrounding rock in different tectonic stresses. As can be seen from Figure 8 , the tectonic stress $\mathrm{F}$ is taken as $k$ times the gravity of the upper rock of tunnel $(k=0.05,0.10,0.15,0.20$, 0.25 ), and lateral pressure coefficient $\lambda=0.5$. With the increase of friction angle, the surrounding rock level is changed from level VI to level I, and the vertical loosening pressure of surrounding rock decreases. As the coefficient $k$ increases, the value of loosening pressure decreases. The larger $k$ is, the lesser the loosening pressure is and the easier it is to reach the bearing limit of surrounding rock and the easier it is to destroy surrounding rock.

4.1.4. The Influence of $h$ on e under Different $\lambda$ Conditions. Compared with conventional geology, the biggest difference of horizontal pressure in anticline area is the consideration of tectonic stress. In general, $\lambda$ is in 0 to 1 , but due to the influence of tectonic stress, $\lambda>1$. Therefore, in the anticline area, $\lambda$ is set to $1.0,1.1,1.2,1.3,1.4$, and 1.5 , and then the relationship between the horizontal surrounding rock 


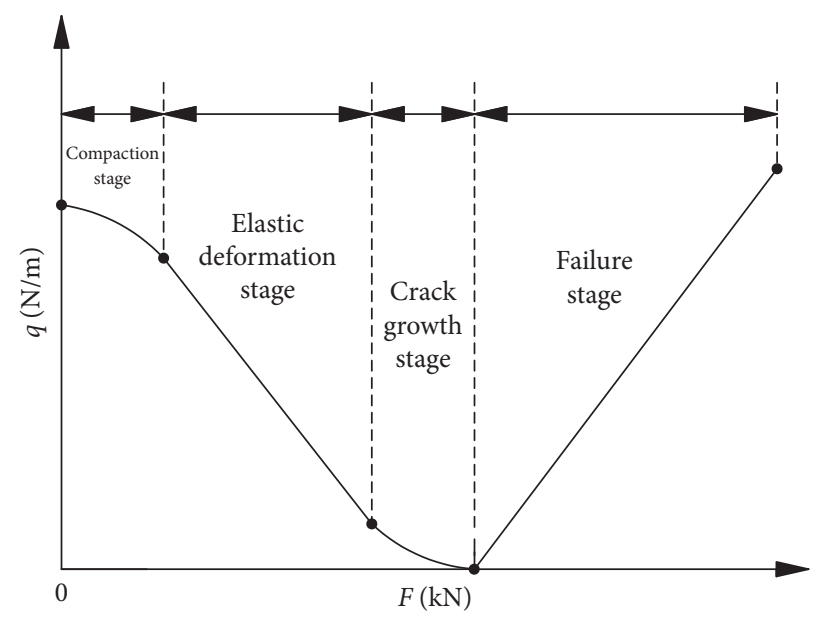

Figure 7: Crustal stress (F)-loose pressure $(\mathrm{q})$ diagram.



Figure 8: Relationship between friction angle $\theta$ and loose pressure $(q) .1-k=0.05 ; 2-k=0.10 ; 3-k=0.15 ; 4-k=0.20 ; 5-k=0.25$; $6-k=0.30$.

loosening pressure with different $\lambda$ parameters and the buried depth of the tunnel is studied. As shown in Figures 9(a) and 9(b), the horizontal loosening pressure of tunnel in oblique area increases with the depth of burial, and the horizontal surrounding rock loosening pressure increases with the increase of lateral pressure coefficient.

4.2. Anticlinal Axis Intersecting Tunnel Centerline. For practical projects, the anticlinal axis is usually not parallel to tunnel centerline. So, there will be a certain angle $(\Delta \varphi)$ between anticlinal axis and tunnel centerline, as shown in Figure 3. Based on the results that anticlinal axis is parallel to tunnel centerline, the unparallel calculation results can be directly obtained as follows.

The total vertical surrounding rock pressure $(P)$ is

$$
P=W_{1}-2 T_{1} \sin \theta-F \sin \left[2\left(\varphi_{1}+\Delta \varphi\right)\right] .
$$

From the trigonometric function theorem:

$$
\frac{T}{\sin \left[90^{\circ}+\left(\varphi_{0}-\varphi_{1}-\Delta \varphi-\beta\right)\right]}=\frac{W_{2}}{\sin \left(\varphi_{1}+\Delta \varphi+\beta-\varphi_{0}-\theta\right)} .
$$

After simplification, we obtain

$$
T=\frac{W_{2} \sin \left[90^{\circ}+\left(\varphi_{0}-\varphi_{1}-\Delta \varphi-\beta\right)\right]}{\sin \left(\varphi_{1}+\Delta \varphi+\beta-\varphi_{0}-\theta\right)}=W_{2}\left[\frac{1}{\tan \left(\varphi_{1}+\Delta \varphi+\beta-\varphi_{0}-\theta\right)}-\tan \theta\right] \cos \theta
$$




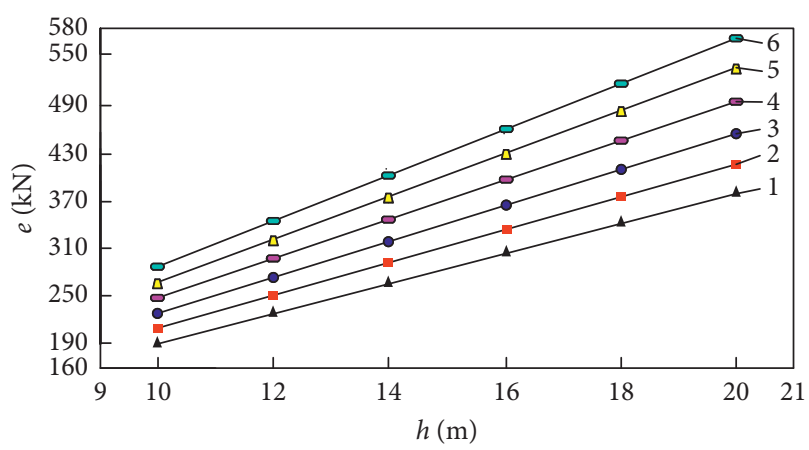

(a)

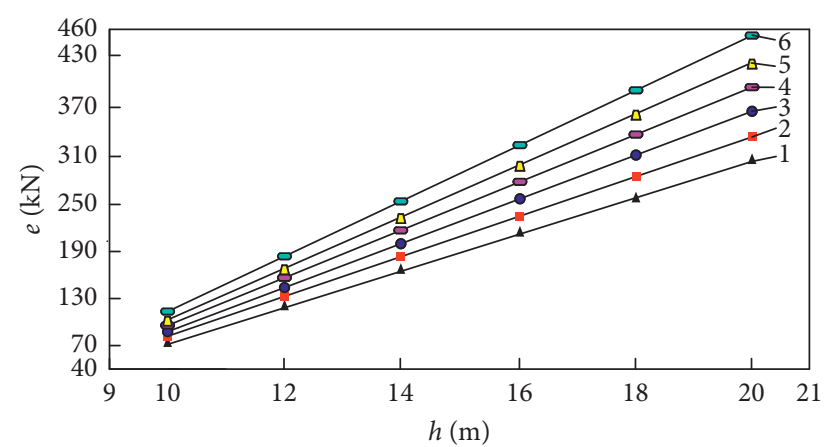

(b)

FiguRE 9: Relationship between tunnel buried depth $h$ and horizontal loosening pressure $e$ of surrounding rock. (a) Horizontal pressure at the top of the tunnel. (b) Horizontal pressure at the bottom of the tunnel. $1-\lambda=1.0 ; 2-\lambda=1.1 ; 3-\lambda=1.2 ; 4-\lambda=1.3 ; 5-\lambda=1.4 ; 6-\lambda=1.5$.

Substitute equation (2) into equation (18) and obtain

$T=\frac{1}{2} \gamma h^{2} \frac{1}{\tan \alpha-\tan \beta}\left[\frac{1}{\tan \left(\varphi_{1}+\Delta \varphi+\beta-\varphi_{0}-\theta\right)}-\tan \theta\right] \cos \theta$.

Next, we make

$\lambda_{1}=\frac{1}{\tan \alpha-\tan \beta}\left[\frac{1}{\tan \left(\varphi_{1}+\Delta \varphi+\beta-\varphi_{0}-\theta\right)}-\tan \theta\right] \cos \theta$.

$$
\begin{aligned}
& \text { If } d \lambda / d \beta=0 \text {, then } \\
& \frac{d\left\{1 / \tan \alpha-\tan \beta\left[1 / \tan \left(\varphi_{1}+\Delta \varphi+\beta-\varphi_{0}-\theta\right)-\tan \theta\right] \cos \theta\right\}}{d \beta}=0 .
\end{aligned}
$$

It is further simplified as

$$
\begin{gathered}
\tan ^{2} \beta\left\{\frac{1}{2} \sin \left[2\left(\phi_{1}+\Delta \phi-\phi_{0}-\theta\right)\right]+\tan \theta \cos \left(\phi_{1}+\Delta \phi-\phi_{0}-\theta\right)\right\} \\
+\tan \beta\left\{2 \sin ^{2}\left(\phi_{1}+\Delta \phi-\phi_{0}-\theta\right)+\tan \theta \sin \left[2\left(\phi_{1}+\Delta \phi-\phi_{0}-\theta\right)\right]\right\} \\
+\left\{\tan \alpha-\frac{1}{2} \sin \left[2\left(\phi_{1}+\Delta \phi-\phi_{0}-\theta\right)\right]-\tan \theta \sin ^{2}\left(\phi_{1}+\Delta \phi-\phi_{0}-\theta\right)\right\}=0, \\
\tan \beta=-\left(2 \sin ^{2} D_{1}+\tan \theta \sin 2 D_{1}\right)+\sqrt{\frac{\left(2 \sin ^{2} D_{1}+\tan \theta \sin 2 D_{1}\right)^{2}-4\left(1 / 2 \sin 2 D_{1}+\tan \theta \cos D_{1}\right)}{\sin 2 D_{1}+2 \tan \theta \cos D_{1}} .}
\end{gathered}
$$

In equation (23), $D_{1}=\left(\varphi_{1}+\Delta \varphi-\varphi_{0}-\theta\right)$.

So,

$$
T=\frac{1}{2} \gamma h^{2} \lambda_{1} .
$$

In equation (24), $\lambda_{1}$ is the lateral pressure coefficient.

The entrainment force $\mathrm{T} 1$ of the two-sided three-ridge rock to the rock (EFGH) is

$$
T=\frac{1}{2} \gamma h_{1}^{2} \lambda_{1} .
$$

The total surrounding rock pressure $(P)$ is obtained as $P=\frac{1}{2} \gamma\left(h_{1}+h_{0}\right) B-\gamma h_{1}^{2} \lambda_{1} \sin \theta-F \sin \left[2\left(\varphi_{1}+\Delta \varphi\right)\right]$.
The vertical surrounding rock loosening pressure $(q)$ is $q=\frac{P}{B}=\frac{1 / 2 \gamma\left(h_{1}+h_{0}\right) B-\gamma h_{1}^{2} \lambda_{1} \sin \theta-F \sin \left[2\left(\varphi_{1}+\Delta \varphi\right)\right]}{B}$.

The horizontal pressure at the top (e1) and bottom (e2) of the tunnel is shown in the following equation:

$$
\left\{\begin{array}{l}
e_{1}=\gamma h_{1} \lambda_{1} \\
e_{2}=\gamma h \lambda_{1} .
\end{array}\right.
$$

There are two ideal situations. In practice, the tunnel is usually not built directly under the V-shaped tip, but the middle line and crimp middle of the tunnel will undergo some deviation, as shown in Figure 10. The difference of deviation $(t)$ will directly affect the value of the surrounding 




FIgURE 10: Calculation model of eccentric compression of tunnel in anticline.

rock loosening pressure. Next, based on the model of anticlinal axis parallel to tunnel centerline, the relationship between the surrounding rock displacement and the surrounding rock loosening pressure is discussed.

The gravity of the rock mass at the top of tunnel is

$$
\begin{aligned}
W_{1} & =\left[\frac{1}{2}\left(h_{3}^{\prime}+h_{0}\right)\left(\frac{B}{2}+t\right)+\frac{1}{2}\left(h_{3}+h_{0}\right)\left(\frac{B}{2}-t\right)\right] \gamma \\
& =\frac{\left(B h_{1}+2 t^{2} \tan \alpha+B h_{0}\right) \gamma}{2} .
\end{aligned}
$$

The vertical surrounding rock loosening pressure $(q)$ is

$$
\begin{aligned}
q= & \frac{P}{B}=\frac{1}{2} \gamma\left(h_{1}+h_{0}-t \cdot \tan \alpha\right)-\frac{\gamma\left(h_{1}-t \cdot \tan \alpha\right)^{2} \lambda \sin \theta}{B} \\
& -\frac{2 F \sin \varphi_{1}}{B} .
\end{aligned}
$$

Take $h 1=14 \mathrm{~m}, h 0=12 \mathrm{~m}, B=5 \mathrm{~m}, \gamma=19 \mathrm{kN} / \mathrm{m}^{3}, \alpha=20^{\circ}$, $\varphi_{1}=30^{\circ}$, and $F=1000 \mathrm{kN} . q$ can be obtained as

$$
\begin{aligned}
q= & -\frac{1}{B} \gamma \tan ^{2} \alpha \lambda \sin \theta \cdot t^{2}+\left(\frac{2}{B} h_{1} \gamma \lambda \tan \alpha \sin \theta-\frac{1}{2} \gamma \tan \alpha\right) t \\
& -\left(\frac{1}{B} \gamma h_{1}^{2} \lambda \sin \theta+\frac{2}{B} F \sin \phi_{1}\right) .
\end{aligned}
$$

Then, we make $a=1 / B \gamma \tan ^{2} \alpha \lambda, b=2 / B h_{1} \gamma \lambda \tan \alpha$, $c=-1 / 2 \gamma \tan \alpha, d=-1 / B \gamma h_{1}^{2} \lambda, e=-2 / B F \sin \varphi_{1}$.

So,

$$
q=-a \cdot \sin \theta \cdot t^{2}+(b \cdot \sin \theta+c) t+(d \cdot \sin \theta+e) .
$$

In equation (32), a, b, c, d, and e are pressure reduction coefficients.
The $\mathrm{q}$ - $\mathrm{t}$ curves at different surrounding rock levels are shown in Figures 11(a)-11(f). It can be seen that $q$ quadratically increases with the increase of $t$. When the variation range of offset is $[-B / 2, B / 2]$, the change rate of loose pressure of surrounding rock is larger; the variation range of offset is $(-\infty,-B / 2] \cup[B / 2, \infty)$; the variation trend of loose pressure of surrounding rock is small. When the tunnel offset is 0 , the process of the surrounding rock level changes from VI to I, and the loosening pressure of surrounding rock decreases gradually. The reason is that the better the grade of surrounding rock, the easier it is to form a pressure arch above the tunnel to resist the external stress and reduce the stress around the tunnel.

The horizontal pressure at the top and bottom of the tunnel is

$$
\begin{cases}e_{1}=\gamma\left(h_{1}-\Delta h\right) \lambda=\gamma\left(h_{1}-t \cdot \tan \alpha\right) \lambda \quad & h_{0}<h^{\prime}<h_{1}, \\ e_{1}=\gamma\left(h_{1}-\Delta h\right) \lambda=\gamma\left(h_{1}+t \cdot \tan \alpha\right) \lambda & h_{1}<h^{\prime}, \\ e_{2}=\gamma(h-\Delta h) \lambda=\gamma(h-t \cdot \tan \alpha) \lambda & h_{0}<h^{\prime}<h_{1}, \\ e_{2}=\gamma(h+\Delta h) \lambda=\gamma(h+t \cdot \tan \alpha) \lambda & h_{1}<h^{\prime} .\end{cases}
$$

From equation (33), it can be seen that with $t$ monotonically increasing, the bottom horizontal surrounding rock pressure is also monotonically decreasing.

\section{Calculation Models of Surrounding Rock Loosening Pressure of Tunnel in the Syncline Zone}

Loosening rock pressure model of tunnel in the syncline zone can also be divided into two situations: (1) the synclinal axis parallel to tunnel centerline, as shown in Figure 2(b); (2) the synclinal axis intersecting the tunnel centerline, as shown in Figure 12. 


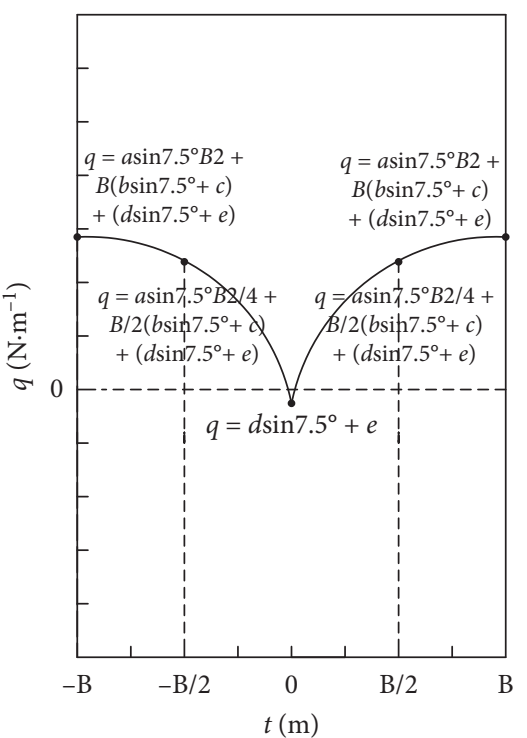

(a)



(d)

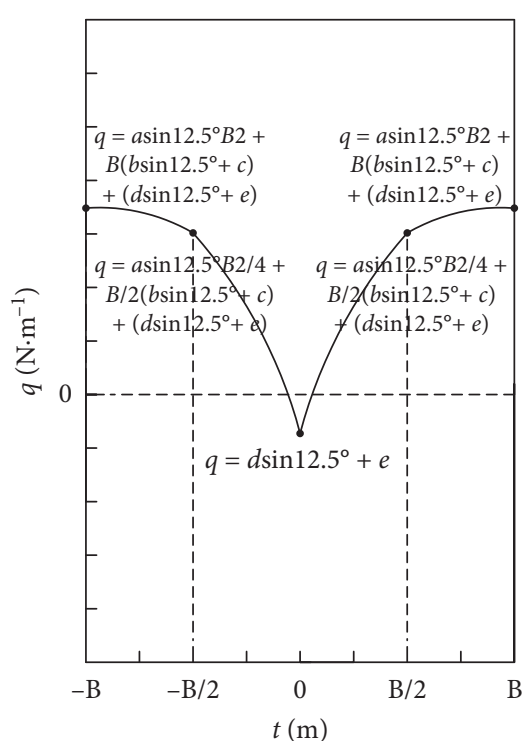

(b)



(e)

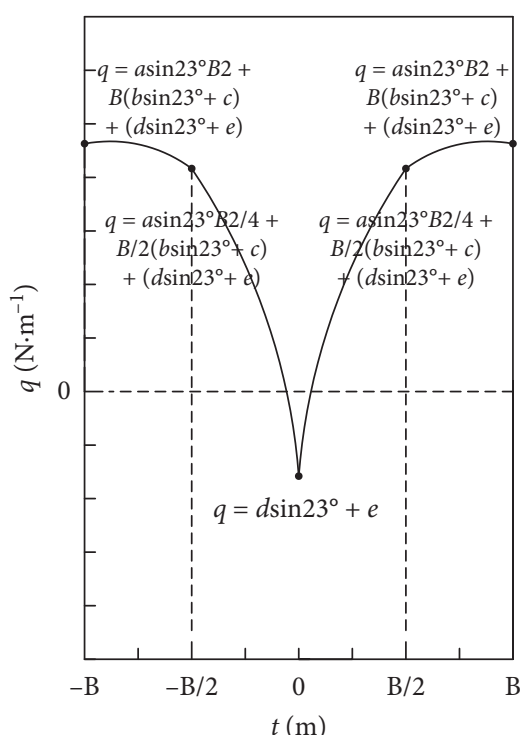

(c)

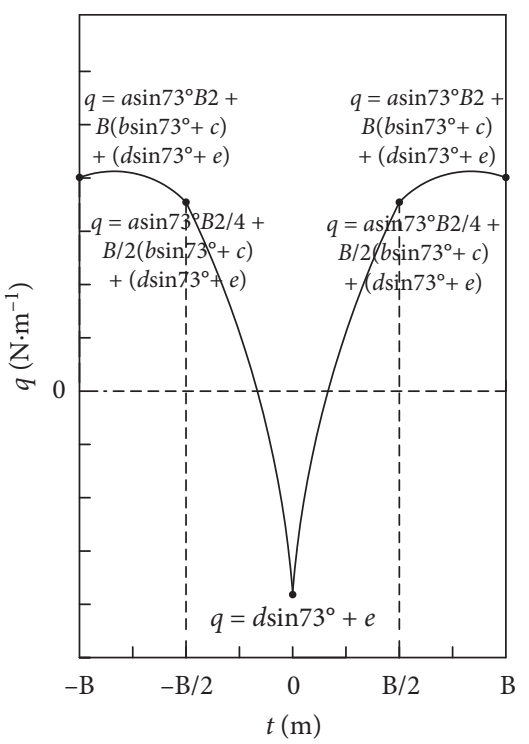

(f)

FIGURE 11: The relationship between $q$ and $(t)$. (a) Class VI surrounding rock zone, $\theta=7.5^{\circ}$. (b) Class V surrounding rock zone, $\theta=12.5^{\circ}$. (c) Class IV surrounding rock zone, $\theta=23^{\circ}$. (d) Class III surrounding rock zone, $\theta=43^{\circ}$. (e) Class II surrounding rock zone, $\theta=60^{\circ}$. (f) Class I surrounding rock zone, $\theta=73^{\circ}$.

5.1. Synclinal Axis Parallel to Tunnel Centerline. Based on the above assumptions, according to the corresponding mechanical principles, the total vertical pressure acting on the support structure is

$$
P=W_{1}-2 T_{1} \sin \theta+F .
$$

In equation (34), $W_{1}=1 / 2 \gamma\left(h_{1}+h_{0}\right) B$.

As $\mathrm{T} 1$ is unknown, the three-ridge $\mathrm{BDF}$ is taken as the research object. The force analysis is shown in Figure 13.

The resistance of the three-ridge rock mass to the sinking rock mass is $T$.

$$
T=\frac{1}{2} \gamma h^{2} \frac{1}{\tan \alpha-\tan \beta} \cdot \frac{\tan \beta-\tan \phi_{0}}{1+\tan \beta\left(\tan \phi_{0}-\tan \theta\right)+\tan \phi_{0} \tan \theta} \cdot \frac{1}{\cos \theta} .
$$




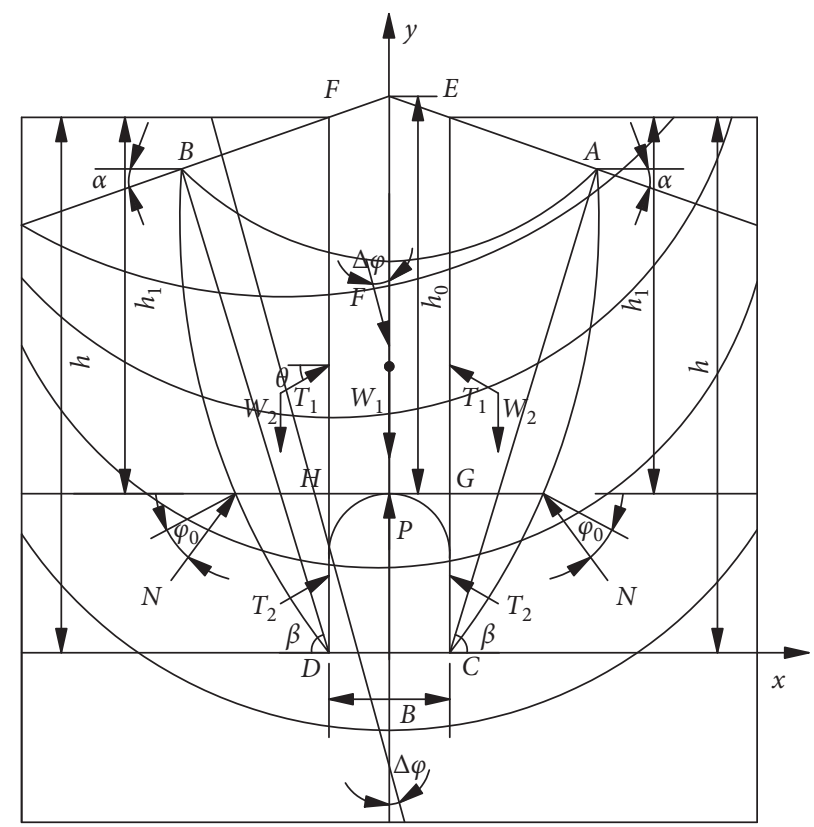

FigURE 12: Surrounding rock loosening rock pressure model of tunnel in the syncline zone.

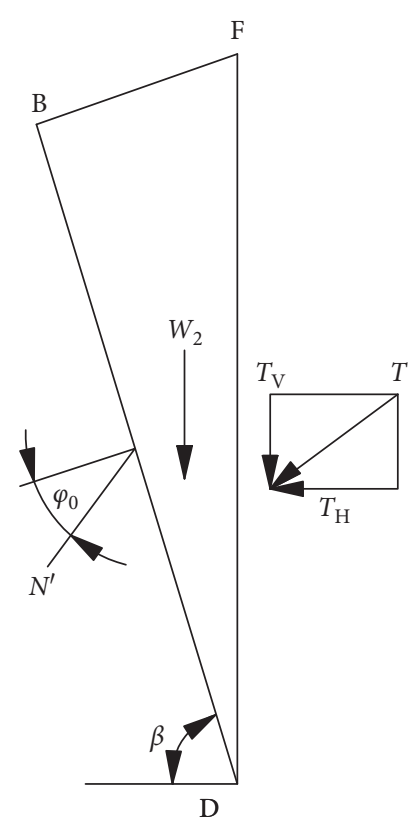

(a)

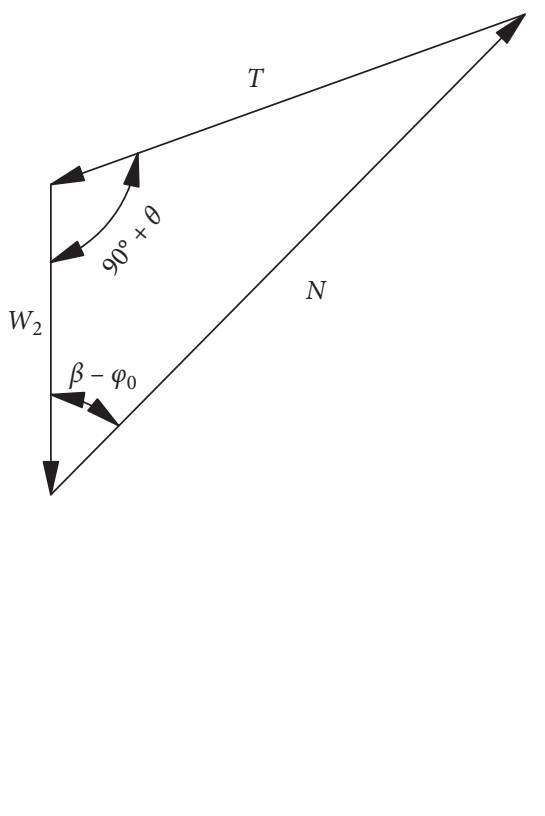

(b)

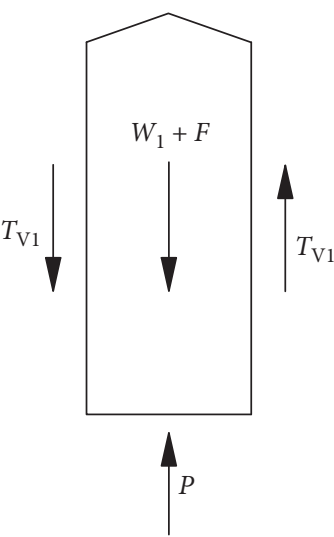

(c)

Figure 13: Rock mass force analysis of BDF and EFHG.

Make

$$
\lambda_{2}=\frac{1}{\tan \alpha-\tan \beta} \cdot \frac{\tan \beta-\tan \phi_{0}}{1+\tan \beta\left(\tan \phi_{0}-\tan \theta\right)+\tan \phi_{0} \tan \theta} .
$$

So,

$$
T=\frac{1}{2} \gamma h^{2} \lambda_{2} \frac{1}{\cos \theta}=\frac{\gamma h^{2} \lambda_{2}}{2 \cos \theta}
$$

In equation (37), $\lambda$ is lateral pressure coefficient.

Then, the resistance force $T 1$ of the two-sided three-ridge rock mass on rock mass (EFGH) is 


$$
T_{1}=\frac{\gamma h_{1}^{2} \lambda_{2}}{2 \cos \theta}
$$

If $d \lambda / d \beta=0$, then

$$
\frac{d\left[1 / \tan \alpha-\tan \beta \cdot \tan \beta-\tan \phi_{0} / 1+\tan \beta\left(\tan \phi_{0}-\tan \theta\right)+\tan \phi_{0} \tan \theta\right]}{d \beta}=0 .
$$

And $\tan \beta$ can be calculated as

$$
\tan \beta=\tan \varphi_{0}+\sqrt{\frac{\left(\tan ^{2} \varphi_{0}+1\right)\left(\tan \varphi_{0}-\tan \alpha\right)}{\tan \varphi_{0}-\tan \theta}} .
$$

Finally, the total surrounding rock pressure $(P)$ is calculated as

$$
P=W_{1}-\gamma h_{1}^{2} \lambda_{2} \tan \theta+F
$$

Vertical surrounding rock loosening pressure is

$$
q=\frac{P}{B}=\frac{1 / 2\left(h_{1}+h_{0}\right) B \gamma-\gamma h_{1}^{2} \lambda_{2} \tan \theta+F}{B} .
$$

Take the single line tunnel section for example. The soil bulk density is $\gamma=19 \mathrm{kN} / \mathrm{m}^{3}, h 1=14 \mathrm{~m}$, and $h 0=12 \mathrm{~m}$. Net width of the tunnel is $B=5 \mathrm{~m}$, lateral pressure coefficient is $\lambda_{2}=(1.0 \sim 1.5)$, and tectonic stress is $F=1000 \mathrm{kN}$. The relation curves between the friction angle $(\theta)$ and the vertical surrounding rock loosening pressure $(q)$ are shown in Figure 14. It can be seen from the figures that with increase of the friction angle $(\theta), q$ gradually decreases, and with the increase of the lateral pressure coefficient, $q$ decreases too. Therefore, the higher the surrounding rock level and the smaller the friction angle $(\theta)$ are, the greater the vertical surrounding rock loosening pressure is.
It can be seen from equation (42) that the vertical surrounding rock loosening pressure $(q)$ is a function of the tectonic stress $(\mathrm{F})$, and $q$ shows a monotonic increasing trend with the increase of tectonic stress.

The horizontal pressure at the top (e1) and bottom (e2) of the tunnel is

$$
\left\{\begin{array}{l}
e_{1}=\gamma h_{1} \lambda_{2} \\
e_{2}=\gamma h \lambda_{2}
\end{array}\right.
$$

As the function relation between the buried depth $(h)$ and the horizontal surrounding rock loosening pressure $(e)$ is similar to that of the anticline zone, only the lateral pressure coefficient is different in it, so it is not analyzed again.

5.2. Synclinal Axis Intersecting Tunnel Centerline. In practice, the synclinal axis intersects the tunnel centerline with a certain angle $(\Delta \varphi)$, as shown in Figure 7 . Based on the calculation results that synclinal axis is parallel to the tunnel centerline, the corresponding calculation results can be obtained as follows.

The total vertical surrounding rock pressure $(P)$ is

$$
P=W_{1}-2 T_{1} \sin \theta+F \cos \Delta \varphi .
$$

The resistant force of the three-ridge rock mass to the sinking rock mass (EFHG) is $T$.

$$
\left.T=\frac{1}{2} \gamma h^{2} \frac{1}{\tan \alpha-\tan \beta} \cdot \frac{\tan \beta-\tan \varphi_{0}}{1+\tan \beta\left(\tan \varphi_{0}-\tan \theta\right)+\tan \varphi_{0} \tan \theta}\right] \frac{1}{\cos \theta} .
$$

Among them,

$$
\lambda_{2}=\frac{1}{\tan \alpha-\tan \beta} \cdot \frac{\tan \beta-\tan \varphi_{0}}{1+\tan \beta\left(\tan \varphi_{0}-\tan \theta\right)+\tan \varphi_{0} \tan \theta} .
$$

So,

$$
T=\frac{1}{2} \gamma h^{2} \lambda_{2} \frac{1}{\cos \theta}=\frac{\gamma h^{2} \lambda_{2}}{2 \cos \theta} .
$$

The entrainment force $\mathrm{T} 1$ of two-sided three-ridge rock on rock mass $(\mathrm{EFGH})$ is

$$
T=\frac{\gamma h_{1}^{2} \lambda_{2}}{2 \cos \theta}
$$

If $\mathrm{d} \lambda / \mathrm{d} \beta=0$, then

$$
\tan \beta=\tan \varphi_{0}+\sqrt{\frac{\left(\tan ^{2} \varphi_{0}+1\right)\left(\tan \varphi_{0}-\tan \alpha\right)}{\tan \varphi_{0}-\tan \theta}} .
$$

The total surrounding rock pressure $(P)$ is calculated as

$$
P=W_{1}-\gamma h_{1}^{2} \lambda_{2} \tan \theta+F \cos \Delta \varphi .
$$

Finally, vertical surrounding rock loosening pressure $(q)$ is

$q=\frac{P}{B}=\left[0.5\left(h_{1}+h_{0}\right) B \gamma-\gamma h_{1}^{2} \lambda_{2} \tan \theta+F \cos \Delta \varphi\right] B^{-1}$. 


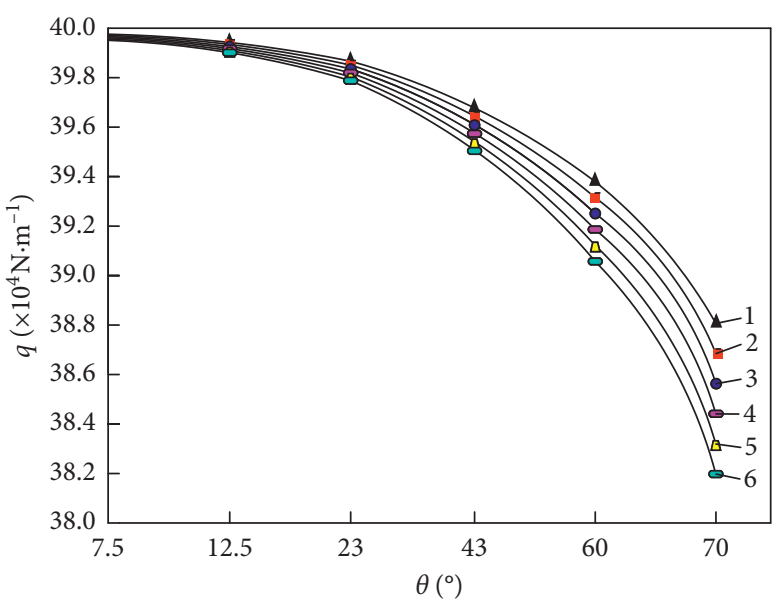

FIGURE 14: Relationship between the friction angle $(\theta)$ and vertical surrounding rock loosening pressure (q). $1-\lambda=1.0 ; 2-\lambda=1.1$; $3-\lambda=1.2 ; 4-\lambda=1.3 ; 5-\lambda=1.4 ; 6-\lambda=1.5$.

When the tunnel passes through the syncline area, because the area under the ${ }^{\wedge}$-shaped tip has the maximum stress, it is necessary to avoid the area to build the tunnel. At this time, there is a corresponding functional relationship between the tunnel displacement and the surrounding rock loosening pressure. The analysis process is similar to that of the anticline area.

Since the lateral pressure coefficient in both cases is the same, the horizontal pressure expressions at the top and bottom of the tunnel are shown in equation (43).

\section{Conclusions}

(1) Under different lateral pressure coefficients, the vertical surrounding rock loosening pressure will increase as $\varphi_{1}$ increases. When the surrounding rock level is VI and the friction angle $\theta=7.5^{\circ}$, vertical loosening pressure has the greatest value. When surrounding rock level is I and the friction angle $\theta=73^{\circ}$, the vertical loosening pressure value is minimal.

(2) In the anticline area, when $q>0$, the surrounding rock is in the elastic deformation stage. As $F$ increases, $q$ decreases monotonously. When $q<0$, representing the onset of failure of rock mass, the number of internal cracks increases and reaches the bearing limit of rock mass. With the continuous increase of $F$, the final rock mass is completely damaged and $q$ grows linearly. The function curves show that the tunnel is located in I, II, and III surrounding rock levels, and loosening pressure is less; when the tunnel is in IV, V, and VI levels, loosening pressure is bigger.

(3) With the increase of friction angle, the surrounding rock level changes from VI to I, and vertical loosening pressure decreases. As the coefficient $k$ increases, the value of loosening pressure decreases. The larger $k$ is, the easier it is to reach its bearing limit and the easier it is to damage.
(4) The horizontal loosening pressure of tunnel in the anticline zone increases with the increase of buried depth, and the horizontal loosening pressure increases with the increase of lateral pressure coefficient.

(5) With the increase of tunnel migration, the vertical loosening pressure increases as a quadratic function. When the process of the surrounding rock level changes from VI to I, loosening surrounding rock pressure decreases.

(6) With the increase of the friction angle $(\theta)$ in the syncline area and lateral pressure coefficient, the vertical loosening pressure gradually decreases. With the increase of surrounding rock level, the friction angle $(\theta)$ decreases, and the vertical loosening pressure increases. The vertical loosening pressure (q) of surrounding rock is related to tectonic stress as a function; the greater $\mathrm{F}$ is, the greater $q$ is $[2-7,25]$.

\section{Nomenclature}

q: Vertical loosening pressure

$\theta$ : Friction angle

$F$ : Tectonic stress

$\varphi_{1}$ : The angle between tectonic stress and horizontal plane

G: Gravity of the rock mass from surface to vault within the tunnel span

$h$ : Buried depth of tunnel

$k$ : $\quad$ The ratio of $F$ to $G$

$\lambda$ : Coefficient of lateral pressure

$h_{q}$ : Height of equivalent load

$\varphi_{0}$ : Angle of equivalent internal friction

$c$ : Cohesion force

$\varphi$ : Inner friction angle.

\section{Data Availability}

The data used to support the findings of this study are included within the article.

\section{Conflicts of Interest}

The authors declare that they have no conflicts of interest.

\section{Acknowledgments}

This study was sponsored by the National Natural Science Foundation of China (grant nos. 51968010 and 51608141) and the Science and Technology Planning Project of Guizhou Province (grant nos. [2012]6024 and [2017]5788).

\section{References}

[1] N. Khezri, H. Mohamad, and B. Fatahi, "Stability assessment of tunnel face in a layered soil using upper bound theorem of limit analysis," Geomechanics and Engineering, vol. 11, no. 4, pp. 471-492, 2016.

[2] A. Argilaga, F. Collin, L. Lacarrière, R. Charlier, G. Armand, and B. Cerfontaine, "Modelling of short-term interactions between concrete support and the excavated damage zone 
around galleries drilled in callovo-oxfordian claystone," International Journal of Civil Engineering, vol. 17, no. 1, pp. 1-18, 2018.

[3] E. B. . Aygar, "Evaluation of new Austrian tunnelling method applied to Bolu tunnel's weak rocks," Journal of Rock Mechanics and Geotechnical Engineering, no. 12, pp. 541-556, 2020.

[4] B. P. De, A. Cuxillier, L. Dormieux et al., "Face stability of shallow circular tunnels driven under the water table: a numerical analysis," International Journal for Numerical \& Analytical Methods in Geomechanics, vol. 23, no. 1, pp. 79-95, 1999.

[5] M. Ghorbani, K. Shahriar, M. Sharifzadeh, and R. Masoudi, "A critical review on the developments of rock support systems in high stress ground conditions," International Journal of Mining Science and Technology, vol. 30, no. 5, pp. 555-572, 2020.

[6] C. J. Xie, J. Y. Rao, Z. Y. Liang et al., "Calculation method of loose pressure of surrounding rock in V-shaped surface shallow burial tunnel," Construction Technology, vol. 47, no. 14 , pp. 33-38, 2018.

[7] Q. Zhang, C. Liu, K. Duan, Z. Zhang, and W. Xiang, "True three-dimensional geomechanical model tests for stability analysis of surrounding rock during the excavation of a deep underground laboratory," Rock Mechanics and Rock Engineering, vol. 53, no. 2, pp. 517-537, 2020.

[8] S. W. Sloan, "Upper bound limit analysis using finite elements and linear programming," International Journal for Numerical \& Analytical Methods in Geomechanics, no. 13, pp. 263282, 1989.

[9] Y. D. Sari, A. Gunhan Pasamehmetoglu, E. Cetiner, and S. Donmez, "Numerical analysis of a tunnel support design in conjunction with empirical methods," International Journal of Geomechanics, vol. 8, no. 1, pp. 74-81, 2008.

[10] F. Sandrone and V. Labiouse, "Analysis of the evolution of road tunnels equilibrium conditions with a convergenceconfinement approach," Rock Mechanics and Rock Engineering, vol. 43, no. 2, pp. 201-218, 2010.

[11] M. Sugimoto, S. Aphichat, and O. Mari, "Tunnel lining design method BY frame structure analysis using ground reaction curve," Journal of Japan Society of Civil Engineers, Ser. C (Geosphere Engineering), vol. 67, no. 1, pp. 61-77, 2011.

[12] Y. Kanoh, G. Bandyopadhyay, M. P. Sajan et al., "Calculation of surrounding rock pressure on shallow buried tunnel using linear and nonlinear failure criterion," Automation in Construction, vol. 37, 2013.

[13] X. Liu and Q. Fang, "Calculation method of loose surrounding rock pressure in shallow buried tunnel with variable slope surface," China Railway Science, vol. 38, no. 2, pp. 64-70, 2017.

[14] P. Li, F. Wang, L. Fan, H. Wang, and G. Ma, "Analytical scrutiny of loosening pressure on deep twin-tunnels in rock formations," Tunnelling and Underground Space Technology, vol. 83, pp. 373-380, 2019.

[15] M. Sugimoto, J. Chen, and A. Sramoon, "Frame structure analysis model of tunnel lining using nonlinear ground reaction curve," Tunnelling and Underground Space Technology, vol. 94, pp. 103135.1-103135.7, 2019.

[16] R. Shakerri, A. Mesgouez, and G. Lefeuve-mesgouez, "Transient response of a concrete tunnel in an elastic rock with imperfect contact," International Journal of Mining Ence and Technology, no. 30, pp. 1-8, 2020.
[17] L. H. Wang, G. H. Wu, Z. G. Su et al., "Study on the mining earthquake law of roadway near the fold-constructed belt," Safety in Coal Mines, vol. 46, no. 2, pp. 40-42, 2015.

[18] M. S. Bensalem, M. Ghanmi, and F. Zargouni, "Genesis of folds in external zones: application of fault propagation fold model. Gafsa Basin example (southern central Tunisia)," Arabian Journal of Geosciences, vol. 4, no. 1-2, pp. 229-237, 2011.

[19] L. Bai, Q. Xu, L. Tian et al., "Model test and analysis of loose zone in soft and cracked surrounding rock of multi-arch tunnel," Yanshilixue Yu Gongcheng Xuebao/Chinese Journal of Rock Mechanics and Engineering, no. 32, pp. 3610-3618, 2013.

[20] C. J. L. Wilson, D. H. Moore, S. A. Vollgger, and H. E. Madeley, "Structural evolution of the orogenic gold deposits in central Victoria, Australia: the role of regional stress change and the tectonic regime," Ore Geology Reviews, vol. 120, p. 103390, 2020.

[21] D. N. Chapman, S. K. Ahn, and D. V. Hunt, "Investigating ground movements caused by the construction of multiple tunnels in soft ground using laboratory model tests," Canadian Geotechnical Journal, vol. 44, no. 6, pp. 631-643, 2007.

[22] L. M. Peng and C. H. Shi, Tunnel Engineering (Version II), Central South University Press, Hunan, China, 2017.

[23] C. B. Guo, Y. H. Zhang, L. W. Jiang et al., "Study on rockburst mechanism and tunnel section suitability of deep tunnels in fold structures," Chinese Journal of Rock Mechanics and Engineering, vol. 31, no. S1, pp. 2758-2766, 2012.

[24] L. H. Wang, "Study on the law of mine movement in the roadway near the fold belt [C]," Proceedings of the 10th National Mining Conference - Topic, Safety Technology and Engineering, vol. 2, , pp. 9-17, 2015.

[25] L. Kang-Hyun, K. Do-Hoon, P. Jegon-Jun et al., "A study on critical strain based damage-controlled test for the evaluation of rock tunnel stability," Journal of Medical Screening, vol. 13, no. 6, pp. 91-107, 2011. 